\title{
A comparison of weighed and recalled intakes for schoolchildren and mothers in rural Kenyat
}

\author{
Constance A Gewa ${ }^{1, *}$, Suzanne P Murphy ${ }^{2}$ and Charlotte G Neumann ${ }^{3}$ \\ 'Department of Global \& Community Health, College of Health \& Human Services, George Mason University, \\ 4400 University Drive MSN 5B7, Fairfax, VA 22030, USA: ${ }^{2}$ Cancer Research Center of Hawaii, University of \\ Hawaii, Honolulu, HI 96813, USA: ${ }^{3}$ Departments of Community Health Sciences and Pediatrics, Schools of \\ Public Health and of Medicine, University of California at Los Angeles, CA 90095, USA
}

Submitted 30 January 2008: Accepted 18 August 2008: First published online 15 September 2008

\begin{abstract}
Objective: To evaluate the relative validity of recalled intake among schoolchildren and mothers in rural Kenya.

Design: Cross-sectional study. Mothers' recall of both the schoolchild's intake and her own intake on the previous day were compared with intakes that were weighed by an interviewer in the home.

Setting: Karurumo location of Embu District in Kenya.

Subjects: A total of forty-two sets of grade 1 students and their mothers.

Results: Between 08.00 and 17.00 hours, when foods were both weighed and recalled, approximately $70 \%$ of weighed food items were recalled the next day. Under-reporting of food amounts was seen across most food categories for the recall, with added sugars, sweets and fats being most affected. The recall underestimated energy intakes by approximately 6-9\% during this period. Correlation coefficients between nutrient intakes ranged from 0.43 to $0 \cdot 65$, while weighted $\kappa$ values ranged from $0 \cdot 22$ to $0 \cdot 50$. Higher levels of agreement were noted for nutrient densities, with correlation coefficients between $0 \cdot 46$ and 0.82 and weighted $\kappa$ values between $0 \cdot 30$ and $0 \cdot 73$.

Conclusions: Although the recall method provides an acceptable alternative to the more labour-intensive and expensive food-weighing method, there is need to further improve its performance in this population through more accurate recall of single foods, especially fruits, as well as added sugars, fats, dairy products and meats, which are often added in small amounts to mixed dishes.
\end{abstract}

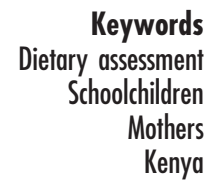

Because of its relative ease of administration and relatively lower respondent burden, the $24 \mathrm{~h}$ recall remains the method of choice for assessing dietary intake among different populations around the world, and still is the most commonly used instrument in dietary assessment in Africa. However, a literature review revealed that few $24 \mathrm{~h}$ recall validation studies have been reported for this region. Those that have been carried out have compared nutrient intakes among pre-school children, women, the elderly and households ${ }^{(1-5)}$. Studies assessing how well the current tools capture schoolchildren's intake are still missing. In the present study, we evaluated the relative validity of recalled intake among schoolchildren and their mothers in rural Kenya by assessing how well mothers can recall the child's

$\uparrow$ Preliminary results of these analyses were presented in a paper entitled 'Diet assessment of school children in rural Kenya: a comparison of weighed observations versus a 24-hour recall' at the Federation of American Societies for Experimental Biology (FASEB) conference, Washington, DC, USA, 17-21 April 2004. as well as their own dietary intake compared with intake measured by weighing the foods that were consumed.

\section{Methods}

The study was conducted in Karurumo location of Embu District in Kenya, where one local elementary school was conveniently selected to participate in the study. All grade 1 students at the school participated in the study. The children were aged 6 to 8 years. Through the students, their households were identified and mothers were requested to participate in the study. Mothers were the main respondents in the study. Informed verbal consent was obtained from the study participants. The study was approved by the UCLA Institutional Review Board and the University of Nairobi Human Subjects Review Board. A total of forty-four schoolchildren and their mothers were selected to participate. 
Estimation guides such as food models, measuring cylinders $(250 \mathrm{ml}$ and $1000 \mathrm{ml})$ and local household measures were utilized during recall interviews. Food models were two-dimensional line drawings of locally available foods in different sizes, while the household measures consisted of spoon, cup and tin measures. A pre-test of the dietary assessments was conducted in non-study households and adjustments made where necessary. Data collection commenced on 4 May 1998 and lasted one month. For each participating household, dietary assessment was conducted on two consecutive weekdays. Participation rates were high with $95 \%$ (forty-two out of forty-four) of households having dietary records for both mother and schoolchild on both days of assessment. Fifty-five per cent of the schoolchildren were male.

\section{Weighed/recalled diet records}

Women with previous experience in dietary data collection methods ${ }^{(6)}$ were recruited as interviewers and re-trained. On the first day of data collection, interviewers arrived at the participating households at 08.00 hours and stayed in the assigned households until 17.00 hours. The interviewers weighed all foods consumed by the schoolchildren and the mothers during that period. They also weighed the ingredients and resulting mixed dish yields produced in the household. All leftover foods were also weighed and recorded. Food servings and ingredients were weighed using the $2 \mathrm{~kg}$ Chatillon scale, which measured to the nearest $5 \mathrm{~g}$, while total mixed recipe yields were weighed using the $25 \mathrm{~kg}$ Salter hanging scale, which measured to the nearest $50 \mathrm{~g}$. The weighing scales were calibrated daily. Before leaving the households at 17.00 hours the interviewers asked the mothers to prepare ingredients that would be used to make the evening meal. These ingredients were then weighed and recorded by the enumerator.

In addition to weighing foods consumed while present in the home, the interviewers also utilized recall methodologies to collect dietary intake information for the remainder of the $24 \mathrm{~h}$ period, following a weighed/ recalled diet records (WRDR) protocol that has been previously used in other validation studies in $\mathrm{Africa}^{(7)}$. On arrival at the household, the interviewer used a recall interview to estimate the foods that had been consumed by the identified schoolchild and the mother from the time they woke up in the morning to 08.00 hours. Recall interviews were also utilized to assess any foods that were consumed outside the home by both mothers and schoolchildren. The school day ended at midday for grade 1 students and they returned home for lunch. Schoolchildren were instructed to report any foods that were consumed outside the home through their mothers. They were also asked to describe the primary ingredients in any mixed dishes consumed or brought from outside the home. The same interviewer returned to the household the following day at 08.00 hours to conduct a recall interview to estimate all the foods that had been prepared and consumed after she had left the household (17.00 hours to bedtime) on the previous day.

\section{$24 \mathrm{~b}$ recall interviews}

A second interviewer visited the household, on the day following the food weighing, to conduct a $24 \mathrm{~h}$ recall of all foods consumed the previous day. Although the WRDR and $24 \mathrm{~h}$ recall interviewers visited the household on this same day, they chose different times to visit with the WRDR interviewer arriving before the $24 \mathrm{~h}$ recall interviewer. Two $24 \mathrm{~h}$ recall interviews were conducted with the mother; the first one focused on the schoolchild's intake and the second one focused on her own intake. A standard $24 \mathrm{~h}$ recall interview was used. The procedures used have been previously described $^{(8)}$. Respondents were asked to estimate amounts of foods consumed, mixed dishes prepared in the home and ingredients used in mixed dishes prepared in the home. Common portion measures were used, and later converted to gram weights using a database developed for this purpose. Mothers were probed about food items consumed and asked to describe the primary ingredients for any mixed dishes brought from outside the home. Standard recipes were used to help determine the nutrient intake from these mixed dishes, for both the recalls and the WRDR. The standard recipes were based on dietary information that had been collected in a previous study in the same study area $^{(6)}$ and were updated to reflect any recipe-content changes that had taken place over the years. Other studies in Africa have reported utilizing standard recipes when actual recipes are not available ${ }^{(1)}$.

\section{Identifying foods that were recalled on the $24 \mathrm{~b}$ recall}

Food items on the WRDR were compared with the $24 \mathrm{~h}$ recall, and were considered matched if the food appeared in both the WRDR and the $24 \mathrm{~h}$ recall interview at approximately the same time of day. Those that appeared only on the WRDR and not on the $24 \mathrm{~h}$ recall were identified as having been omitted by the $24 \mathrm{~h}$ recall. If a food item in the WRDR was similar to another on the $24 \mathrm{~h}$ recall and appeared at approximately the same time, we did not count it as a missed food but it was identified as a mis-specified food item. Mis-specified foods had the same main ingredients with slight changes in the other remaining ingredients. Foods that appeared only on the $24 \mathrm{~h}$ recall and not on the WRDR were identified as intrusions by the $24 \mathrm{~h}$ recall.

\section{Food group and nutrient intake calculations}

Food groups of interest included starchy foods, vegetables, fruits, dairy, meats (includes wild and domesticated animals, insects and fish), legumes and/or nuts, high-fat foods/fats/ oils, added sugars and sweets, and beverages (tea, cocoa and coffee). Single food items and ingredients in food mixtures were each assigned to the appropriate food group. Nutrient intakes were calculated for each individual using 
an international food composition table which was adapted for use in the present study (University of California, Berkeley, CA, USA) ${ }^{(9)}$. This table contains complete nutrient values for the common foods consumed in rural Kenya. The nutrient contents of less common foods were estimated from similar foods. Nutrients of interest included energy, carbohydrates, total protein, fat, total Fe, total Zn, $\mathrm{Ca}$, vitamins $\mathrm{A}$ and $\mathrm{C}$, and riboflavin.

\section{Statistical analysis}

Data analysis was carried out using the SAS statistical software program version 8.2 (SAS Institute, Cary, NC, USA). A total of forty-two households with a WRDR and $24 \mathrm{~h}$ recall for both the mother and schoolchild were included in the analysis. Ratios between recalled and weighed amounts (in grams) were calculated for the different food groups for those who mentioned the food group in either one of the methods. Differences between nutrient amounts from the two methods were assessed using Wilcoxon's signed-rank test. Spearman's ranked correlations were utilized to assess association between the two methods. Agreement between methods was further assessed by Bland-Altman and limits of agreement (LOA) plots ${ }^{(10)}$. Differences between the two methods were plotted against the average of the two methods to examine the spread of the differences between the two methods and the presence of any systemic bias. The joint classification of nutrients by the two methods was assessed using quartiles of intake for each nutrient for each of the methods. The proportion correctly classified reflects how often an individual's intake fell in the same quartile using both methods. The proportion that was grossly misclassified reflects how often one method assigned an individual's intake into the lowest quartile and the other method assigned it into the highest quartile. Weighted $\kappa$ values are presented. An $\alpha$ level of 0.05 was used to indicate statistical significance.

\section{Results}

\section{Nutrient intake estimates}

Energy intake for the full $24 \mathrm{~h}$ period was 7883 (SD 3414) kJ (1884 (SD 816) kcal) for the WRDR method and 7301 (SD 3464) kJ (1745 (SD 828) kcal) for the recall method for the schoolchildren. For the mothers, intake was 9037 (SD 4159) kJ (2160 (SD 994) kcal) for the WRDR method compared with 8594 (sD 3410) kJ (2054 (sD 815) kcal) for the recall method. Thus, the recall method underestimated total intake by approximately $7 \%$ for the children and by $5 \%$ for the mothers. To further investigate this difference, we examined foods consumed at different time periods: before 08.00 hours, between 08.00 and 17.00 hours, and after 17.00 hours. Small differences were seen between the foods consumed before 08.00 hours and those consumed after 17.00 hours, when intakes were recalled by both the WRDR and $24 \mathrm{~h}$ recall methods.
These differences may be attributed to slightly different methodologies for the recalls during these time periods. However, for the remaining analyses, we focus on foods consumed between 08.00 and 17.00 hours, when most of the foods were weighed within the WRDR. Thus, the WRDR during this time period should be an accurate standard to which the recalled intakes can be compared.

Approximately 50\% of the schoolchildren's and mothers' food items were consumed between 08.00 hours and 17.00 hours and provided approximately $50 \%$ of the daily energy intake. The number of food items consumed during this time period ranged from one to seven for the schoolchildren and mothers. Most of the food items (84\% and $94 \%$ of schoolchildren's and mothers' food items, respectively) consumed during this period were estimated by direct weighing on the first day of data collection. Sixty-eight per cent of the schoolchildren's and $73 \%$ of the mothers' intakes were matched in the $24 \mathrm{~h}$ recall. Overall, $21 \%$ and 15\% were omitted from the $24 \mathrm{~h}$ recall, and approximately $10 \%$ were mis-specified within the $24 \mathrm{~h}$ recall. Of the food items on the recalls, $8 \%$ and $10 \%$ were not present in the weighed records.

Nutrient intake estimates from the $24 \mathrm{~h}$ recall for this time period were generally lower compared with those from the weighed records (Table 1). Energy intakes were lower by $9 \%$ for the children and by $6 \%$ for the mothers. Significant between-method differences in absolute intakes were noted only for vitamins A and C for both the schoolchildren and the mothers. When intakes were expressed as nutrient densities (nutrient per $4184 \mathrm{~kJ}$ ), vitamin A intake remained significantly different for the schoolchildren while Ca intake became significantly different for the mothers. Correlation coefficients between absolute nutrient intakes for the two methods ranged from 0.49 to 0.64 for the schoolchildren's intakes and from 0.43 to 0.65 for mothers' intakes (Table 2). Correlation coefficients were higher for most of the nutrient densities, with only one value being below 0.50 and a majority of them being above $0 \cdot 60$. All correlation coefficient values for both the absolute nutrients and nutrient densities were statistically significant.

For the schoolchildren, Bland-Altman plots show that the mean differences between $24 \mathrm{~h}$ recall and weighed records for the nutrient densities were small, with the individual differences generally clustered around zero (Fig. 1). Most of the nutrient density values fell within the 95\% LOA for all nutrients. Between-method differences appeared to increase as mean intake increased for fat and vitamins A and C, suggesting a violation of the assumption of constant variance. Such violations were not noted for the other nutrients. The plots for the mothers' intakes were similar (data not shown).

The joint classification ranged from fair to moderate ${ }^{(11)}$, with weighted $\kappa$ values ranging from 0.30 to 0.50 for the schoolchildren's absolute nutrient intakes and from $0 \cdot 22$ 
Table 1 Nutrient intake estimated from weighed foods and from a $24 \mathrm{~h}$ recall between $08 \cdot 00$ hours and $17 \cdot 00$ hours: schoolchildren $(n 42)$ and their mothers ( $n$ 42), Kenya, May 1998

\begin{tabular}{|c|c|c|c|c|c|c|c|c|}
\hline & \multicolumn{4}{|c|}{ Schoolchildren } & \multicolumn{4}{|c|}{ Mothers } \\
\hline & \multicolumn{2}{|c|}{ Weighed } & \multicolumn{2}{|c|}{ Recalled } & \multicolumn{2}{|c|}{ Weighed } & \multicolumn{2}{|c|}{ Recalled } \\
\hline & Mean & SD & Mean & SD & Mean & SD & Mean & SD \\
\hline \multicolumn{9}{|c|}{ Absolute nutrient intakes } \\
\hline Energy (kJ) & 4042 & 1895 & 3682 & 2218 & 4606 & 2238 & 4322 & 1904 \\
\hline Energy (kcal) & 966 & 453 & 880 & 530 & 1101 & 535 & 1033 & 455 \\
\hline Carbohydrate (g) & 188 & 87 & 171 & 108 & 217 & 110 & 205 & 91 \\
\hline Fat $(\mathrm{g})$ & 16 & 11 & 14 & 9 & 17 & 12 & 15 & 9 \\
\hline Protein (g) & 28 & 18 & 26 & 19 & 31 & 18 & 31 & 16 \\
\hline $\mathrm{Ca}(\mathrm{mg})$ & 234 & 223 & 172 & 108 & 275 & 248 & 189 & 138 \\
\hline $\mathrm{Fe}(\mathrm{mg})$ & $11 \cdot 0$ & $7 \cdot 5$ & $10 \cdot 0$ & $7 \cdot 4$ & $12 \cdot 2$ & $8 \cdot 2$ & $11 \cdot 8$ & 6 \\
\hline $\mathrm{Zn}(\mathrm{mg})$ & $4 \cdot 8$ & $2 \cdot 9$ & $4 \cdot 6$ & $3 \cdot 2$ & $5 \cdot 3$ & $3 \cdot 0$ & $5 \cdot 4$ & $2 \cdot 8$ \\
\hline Riboflavin (mg) & 0.66 & 0.38 & 0.59 & $0 \cdot 32$ & 0.73 & 0.40 & 0.67 & 0.30 \\
\hline Vitamin A (RAE) & 320 & 436 & $174^{\star}$ & 148 & 307 & 341 & $188^{*}$ & 191 \\
\hline Vitamin C (mg) & 103 & 119 & $73^{*}$ & 98 & 67 & 62 & $45^{*}$ & 45 \\
\hline \multicolumn{9}{|c|}{ Nutrient intakes per $4184 \mathrm{~kJ}$} \\
\hline Carbohydrate (g) & 197 & 21 & 195 & 23 & 197 & 22 & 199 & 19 \\
\hline Fat $(\mathrm{g})$ & 16 & 9 & 17 & 11 & 16 & 9 & 14 & 8 \\
\hline Protein (g) & 29 & 7 & 29 & 7 & 29 & 8 & 29 & 7 \\
\hline $\mathrm{Ca}(\mathrm{mg})$ & 231 & 126 & 205 & 115 & 246 & 160 & $190^{*}$ & 134 \\
\hline $\mathrm{Fe}(\mathrm{mg})$ & 11 & 3 & 11 & 3 & 11 & 3 & 11 & 3 \\
\hline $\mathrm{Zn}(\mathrm{mg})$ & $4 \cdot 8$ & 1 & 5 & 1 & 5 & 1 & 5 & 1 \\
\hline Riboflavin (mg) & $0 \cdot 70$ & $0 \cdot 10$ & $0 \cdot 70$ & $0 \cdot 17$ & $0 \cdot 70$ & $0 \cdot 18$ & 0.66 & $0 \cdot 19$ \\
\hline Vitamin A (RAE) & 319 & 362 & $214^{\star}$ & 178 & 272 & 246 & 206 & 203 \\
\hline Vitamin C (mg) & 131 & 220 & 103 & 145 & 77 & 120 & 52 & 51 \\
\hline
\end{tabular}

RAE, retinol activity equivalent.

Mean values from the recall were significantly different from those weighed using Wilcoxon's signed-rank test: ${ }^{\star} P<0 \cdot 05$.

Table 2 Spearman correlation, nutrient classification and weighted $\kappa$ values between weighed and recalled nutrient intakes between $08 \cdot 00$ hours and 17.00 hours: schoolchildren ( $n$ 42) and their mothers ( $n$ 42), Kenya, May 1998

\begin{tabular}{|c|c|c|c|c|c|c|c|c|}
\hline & \multicolumn{4}{|c|}{ Schoolchildren } & \multicolumn{4}{|c|}{ Mothers } \\
\hline & \multirow[b]{2}{*}{$\rho$} & \multicolumn{3}{|c|}{ Classification } & \multirow[b]{2}{*}{$\rho$} & \multicolumn{3}{|c|}{ Classification } \\
\hline & & $\% \mathrm{Cc}$ & Wk & $95 \% \mathrm{Cl}$ of $\mathrm{Wk}$ & & $\% \mathrm{Cc}$ & Wk & $95 \% \mathrm{Cl}$ of $\mathrm{Wk}$ \\
\hline \multicolumn{9}{|c|}{ Absolute nutrient intakes } \\
\hline Energy $(\mathrm{kJ})$ & $0 \cdot 51$ & 29 & $0 \cdot 30$ & $0 \cdot 12,0 \cdot 48$ & 0.44 & 36 & $0 \cdot 26$ & $0.06,0.47$ \\
\hline Carbohydrate (g) & 0.49 & 40 & $0 \cdot 34$ & $0.14,0.53$ & 0.45 & 31 & $0 \cdot 22$ & $0.02,0.43$ \\
\hline Fat $(\mathrm{g})$ & 0.56 & 45 & 0.42 & $0 \cdot 22,0.61$ & 0.65 & 45 & 0.46 & $0.26,0.65$ \\
\hline Protein (g) & 0.63 & 48 & 0.50 & $0.31,0.68$ & 0.56 & 33 & 0.34 & $0.15,0.53$ \\
\hline $\mathrm{Ca}(\mathrm{mg})$ & $0 \cdot 60$ & 38 & $0 \cdot 42$ & $0.23,0.60$ & $0 \cdot 50$ & 43 & $0 \cdot 38$ & $0.17,0.59$ \\
\hline $\mathrm{Fe}(\mathrm{mg})$ & 0.64 & 45 & 0.46 & $0.26,0.65$ & 0.56 & 36 & 0.26 & $0.06,0.47$ \\
\hline $\mathrm{Zn}(\mathrm{mg})$ & $0 \cdot 62$ & 48 & 0.50 & $0.31,0.68$ & 0.55 & 38 & $0 \cdot 30$ & $0.09,0.51$ \\
\hline Riboflavin (mg) & 0.56 & 31 & $0 \cdot 34$ & $0.17,0.51$ & 0.48 & 36 & $0 \cdot 34$ & $0 \cdot 15,0.53$ \\
\hline Vitamin A (RAE) & 0.62 & 48 & 0.46 & $0.27,0.65$ & 0.49 & 41 & $0 \cdot 38$ & $0.17,0.58$ \\
\hline Vitamin C (mg) & $0 \cdot 50$ & 38 & $0 \cdot 30$ & $0.08,0.52$ & 0.43 & 48 & $0 \cdot 34$ & $0 \cdot 10,0.58$ \\
\hline \multicolumn{9}{|c|}{ Nutrient intakes per $4184 \mathrm{~kJ}$} \\
\hline Carbohydrate (g) & $0 \cdot 68$ & 55 & 0.53 & $0.35,0.72$ & $0 \cdot 75$ & 52 & $0 \cdot 50$ & $0.30,0.69$ \\
\hline Fat $(\mathrm{g})$ & $0 \cdot 72$ & 60 & 0.57 & $0 \cdot 38,0 \cdot 76$ & $0 \cdot 82$ & 67 & 0.69 & $0.53,0.84$ \\
\hline Protein (g) & $0 \cdot 74$ & 50 & 0.53 & $0 \cdot 36,0.71$ & $0 \cdot 85$ & 71 & 0.73 & $0.58,0.87$ \\
\hline $\mathrm{Ca}(\mathrm{mg})$ & 0.51 & 48 & 0.38 & $0.16,0.60$ & 0.46 & 41 & $0 \cdot 34$ & $0.13,0.55$ \\
\hline $\mathrm{Fe}(\mathrm{mg})$ & 0.75 & 52 & 0.50 & $0.30,0.69$ & $0 \cdot 73$ & 64 & 0.61 & $0 \cdot 42,0.80$ \\
\hline $\mathrm{Zn}(\mathrm{mg})$ & $0 \cdot 76$ & 48 & 0.53 & $0.37,0.70$ & $0 \cdot 82$ & 60 & $0 \cdot 61$ & $0.45,0.77$ \\
\hline Riboflavin (mg) & 0.53 & 57 & 0.50 & $0 \cdot 29,0 \cdot 70$ & $0 \cdot 60$ & 65 & $0 \cdot 42$ & $0 \cdot 22,0 \cdot 61$ \\
\hline Vitamin A (RAE) & 0.58 & 50 & $0 \cdot 46$ & $0.25,0.66$ & 0.57 & 50 & 0.46 & $0.25,0.66$ \\
\hline Vitamin C (mg) & 0.62 & 48 & 0.46 & $0 \cdot 26,0.65$ & 0.66 & 52 & $0 \cdot 50$ & $0.30,0.69$ \\
\hline
\end{tabular}

$\rho$, Spearman's correlation; \%Cc, percentage correctly classified; Wk, weighted $\kappa$; RAE, retinol activity equivalent.

All correlation coefficients and weighted $\kappa$ values were statistically significant: $P<0.05$.

to $0 \cdot 46$ for the mothers' intakes (Table 2 ). The proportion of absolute nutrient intakes that were classified within the same quartile ranged from $29 \%$ to $48 \%$ for schoolchildren and from $31 \%$ to $48 \%$ for mothers. Gross misclassification was very low, ranging from 0 to $5 \%$. Joint classification and weighted $\kappa$ values were considerably higher for most of the nutrient densities, showing fair to moderate agreement for schoolchildren and fair to good agreement for mothers ${ }^{(11)}$. 

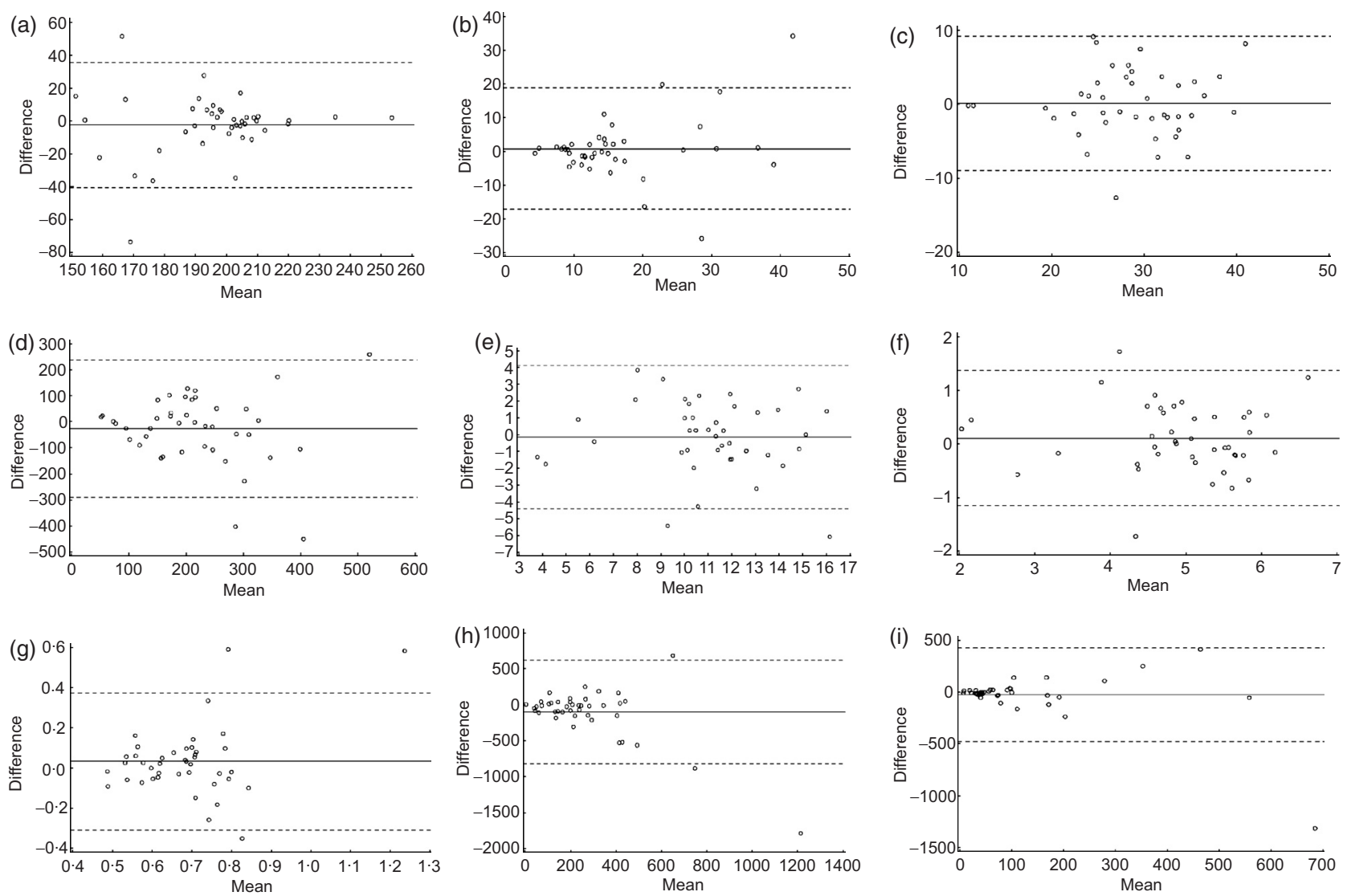

Fig. 1 Bland-Altman plots of the difference between recalled and weighed nutrient intakes, expressed per $4184 \mathrm{~kJ}$, for Kenyan schoolchildren (n 42): (a) carbohydrate (g); (b) fat (g); (c) protein (g); (d) calcium (mg); (e) iron (mg); (f) zinc (mg); (g) riboflavin (mg); (h) vitamin A ( $\mu$ g retinol activity equivalent); and (i) vitamin C (mg). - . - -, upper and lower limits of agreement; $-\frac{}{-}$, mean difference

Under-reporting of food amounts was seen across most food categories for the recall (Table 3). Added sugars and sweets and fats were particularly low relative to the weighed intakes, for both schoolchildren and mothers. Reported levels of dairy and beverages were also notably lower than the weighed amounts in the mother's diets, while meats were lower in the diets of the four children who reported meat intake. Beverage intake was overreported, on average, for the children.

\section{Omissions and intrusions on the recall}

Fifty per cent (21 out of 42) of the schoolchildren and $31 \%$ (13 out of 42 ) of the mothers had at least one weighed food item that was omitted from the recalled intake. A majority of the omitted foods were single food items, especially fruits.

Foods that appeared only on the $24 \mathrm{~h}$ recall and not on the WRDR were identified as intrusions on the $24 \mathrm{~h}$ recall. Twenty-one per cent ( 9 out of 42) of the schoolchildren and $19 \%$ ( 8 out of 42 ) of the mothers had at least one food item identified as an intrusion on the $24 \mathrm{~h}$ recall. A majority of the intrusions were fruits, and most of these fruits appeared to replace those that had been omitted. Thus, these fruit items might be considered possible
Table 3 Ratio (expressed as a percentage) of recalled to weighed mean intakes $(\mathrm{g} / \mathrm{d})$ between $08 \cdot 00$ hours and 17.00 hours for the main food groups consumed (only for subjects who reported the food group for at least one of the methods): schoolchildren ( $n$ 42) and their mothers ( $n$ 42), Kenya, May 1998

\begin{tabular}{lccrcc}
\hline & \multicolumn{2}{c}{ Schoolchildren } & & \multicolumn{2}{c}{ Mothers } \\
\cline { 2 - 3 } \cline { 5 - 6 } Food type & $n$ & Ratio (\%) & & $n$ & Ratio (\%) \\
\hline Starchy foods & 42 & 81 & & 41 & 93 \\
Vegetables & 40 & 73 & & 38 & 73 \\
Fruits & 24 & 100 & & 19 & 75 \\
Dairy & 14 & 99 & & 22 & 64 \\
Meats & 4 & 63 & & 4 & 84 \\
Legumes/nuts & 35 & 100 & & 35 & 113 \\
Fats & 31 & 61 & & 29 & 55 \\
Added sugars \& sweets & 23 & 43 & & 27 & 31 \\
Beverages & 12 & 127 & & 19 & 70 \\
\hline
\end{tabular}

indications of mis-specifications instead of being complete omissions. As shown in Table 3, 100\% of the amount of the fruit food group on the weighed intakes was present on the recalled intakes for the children, although the specific type fruit may have been different. The percentage of the fruit food group that was recalled was lower for the mothers' recalls $(75 \%)$, probably indicating that more true omissions occurred. 


\section{Discussion}

In the current study, most of the weighed food items (approximately 70\%) were reported on the $24 \mathrm{~h}$ recall. Approximately $10 \%$ of the food items were mis-specified, and $15-20 \%$ were omitted on the recall. There were very low levels of food intrusions. Most of the foods that were omitted or added were single food item snacks, with fruits making up the highest proportion of these foods. Further examination of the foods added to the recalls indicated possible mis-specification of these fruits.

The results showed lower mean intake levels for both foods and nutrients from the recall method than from the weighed method, with differences being more evident with the schoolchildren's intakes. Under-reporting on dietary recalls has been reported in many countries ${ }^{(12-14)}$, although the magnitude of the bias is often greater than what was seen in this study in Kenya. Underestimation was seen across most of the food categories (Table 3). The energyrelated errors may have resulted from underestimation of fats and added sugars. Errors in estimating energy intake, arising mostly from estimation of snack foods and main staples, have been previously noted among Ghanian children and rural Malawian women, respectively ${ }^{(1,15)}$.

The correlation coefficients were relatively high for most of the nutrients of interest in our study (at least $0 \cdot 47$ for the schoolchildren and at least 0.43 for the mothers), indicating that the intakes were ranked similarly by the two methods. Weighted $\kappa$ values and proportions of nutrients classified into the same categories were fair to moderate, while gross misclassification was low for all nutrients, illustrating that the recall ranks schoolchildren's and mothers' intakes moderately well.

The nutrient densities showed smaller mean differences and higher correlation coefficients, as well as higher weighted $\kappa$ values and percentages of nutrients classified into the same quartile, indicating that adjustment for differences in energy intake removes much of the difference and increases the level of agreement in nutrient intake. This also suggests that between-method differences may have resulted more from differences in the quantity of foods, rather than differences in the type or mix of foods consumed. Heteroscedasticity was noted for fat and vitamins A and C, which may lead to an underestimation of the standard errors but should not bias the correlation coefficients ${ }^{(16)}$.

\section{Comparison with other validation studies}

Dop et al. concluded that two $24 \mathrm{~h}$ recalls were as precise as a single day's weighed records among weanlings in Senegal $^{(5)}$. Kigutha found no significant differences in mean nutrient intakes when comparing repeated $24 \mathrm{~h}$ recalls and weighed food records among pre-school children and elderly people in rural Kenya. However, she also noted that the $24 \mathrm{~h}$ recall had a tendency to overestimate $\mathrm{Fe}$, $\mathrm{Ca}$ and vitamin $\mathrm{A}$ and $\mathrm{C}$ intakes among preschool children and to underestimate energy, protein, fat, thiamin and niacin among the elderly ${ }^{(2)}$. However, the study did not go beyond the use of correlations to compare the relative ranking of intakes with the two methods. Ferguson et al. noted that the $24 \mathrm{~h}$ recall performed poorly in estimating portion sizes of main staples, soups and fruits among Ghanian pre-school children and main staples and relishes among women in rural Malawi ${ }^{(1,15)}$. The authors concluded that the $24 \mathrm{~h}$ recall performed better in categorizing individuals according to their dietary patterns rather than in estimating absolute daily intakes ${ }^{(1,15)}$.

There are several strengths of the present analysis, including the availability of weighed intakes during the period of 08.00 to 17.00 hours. Also, our extensive food composition table allowed us to compare intakes of a variety of nutrients and food groups. Although our sample size is relatively small ( $n 42$ for both schoolchildren and mothers), there was sufficient power to detect intake differences as small as $10 \%$ for most nutrients. Although a multi-day study, with a full $24 \mathrm{~h}$ period of weighed intakes, would have been desirable ${ }^{(17)}$, funds were not available to extend the intensive weighed intake method.

The presence of an enumerator in the household for the WRDR may have influenced household dietary behaviour. However, the schoolchildren's mean daily energy intake in the present study was close to that reported using $24 \mathrm{~h}$ recalls in a larger study of other children in the same area ${ }^{(18)}$. No recent data are available for adult females in this area of Kenya, but the mothers' mean energy intake levels were higher than those reported in the study population in $1984-5^{(6)}$. However, this increase may reflect dietary changes that have taken place over the years, because similar increases have been noted in the schoolchildren's nutrient intake ${ }^{(18)}$.

A large nutrition study was conducted in this district of Kenya almost 15 years ago, but due to the long time lag, it is unlikely that the young mothers who participated in the current study would have an increased awareness of their food intake as a result. Thus, these findings should be applicable to similar populations in other communities.

\section{Strengths and weaknesses of the two methods}

The weighed method should provide an accurate estimate of food intake during the time that the enumerator is in the home. However, this method has several limitations for large nutrition studies. It is a relatively expensive method because it requires the presence of an enumerator for all or part of the period being studied. It is seldom feasible for the enumerator to remain in the household overnight, so foods prepared and consumed between 17.00 hours and 08.00 hours the next morning must be estimated via a recall method. If it is necessary to collect multiple days of dietary data, as is usually the case, then the cost of data collection can be prohibitive. Finally, the presence of the enumerator in the home may alter food habits, so that the resulting intake data do not reflect usual intakes. In some cultures, the presence of a stranger in the home may be considered unacceptable. 
The recall method of collecting intakes is often chosen to reduce the expense of collecting intake data. However, as we found in our study, intakes are likely to be underestimated due to errors of omission, mis-specification of foods and incorrect estimates of amounts consumed. Furthermore, accurate intake estimates require a convenient method of converting common portion sizes into gram weights. For our study, we developed a database of almost 2500 entries that allowed us to automatically convert common measures, such as a piece of fruit or a cup of milk, into the corresponding gram weight. However, once developed, such a database can be used for further studies in the same area or, with some modifications, for studies in similar populations elsewhere.

Neither method can accurately capture foods consumed outside the home, which may be particularly important for schoolchildren ${ }^{(19)}$. Because the interviewer is present in the home during the day for the weighing method, it is possible to ask both adults and children about foods consumed elsewhere at the time they return from school or other activities outside the home. However, we found similar reporting of mixed dishes consumed outside the home with the two methods: $5 \%$ and 3\% of the mixed dishes for the mothers' and schoolchildren's intakes from the weighed records, and $4 \%$ for both groups from the recalls. As children grow older and spend more time outside the home, the number of foods consumed outside the home is expected to rise, thus making it more difficult for mothers to recall the children's intakes. Thus, the study's results should be generalized primarily to mothers' abilities to recall their own intake and that of their young children who still rely heavily on them for their daily intake. As children grow older, they should be encouraged to participate more prominently in reporting their own dietary intake.

In conclusion, in our study the recall method underestimated energy intake by about $6 \%$ for the mothers and $9 \%$ for the children compared with weighed records between 8.00 and 17.00 hours. Furthermore, recalls provided a relatively good method of ranking and classifying nutrient intake. The recall method performed better when comparing nutrient densities, suggesting that estimates of absolute nutrient values and of energy intake should be interpreted with more caution. To further improve $24 \mathrm{~h}$ recall performance in this population, there is a need to improve the recall of single foods, especially fruits, and that of added sugars, fats, dairy products and meats, which are often added in small amounts to mixed dishes. Because weighing all foods consumed is not feasible in most large studies, the $24 \mathrm{~h}$ recall method provides an acceptable alternative.

\section{Acknowledgements}

Source of funding: The work was supported by the Global Livestock Collaborative Research Support Program, University of California at Davis, through the US
Agency for International Development grant number PCE-G-00-98-00036-00.

Conflict of interest declaration: None.

Authorship responsibilities: C.A.G. was the nutritionist responsible for dietary data collection and data analysis for the study. S.P.M. was a co-investigator for the study and was responsible for the design of the dietary data collection methodology and helped guide data analysis. C.G.N. was the principal investigator for the study. All co-authors contributed to the writing of this paper.

Acknowledgments: We acknowledge Dr Nimrod Bwibo, the Kenyan Co-PI of the Child Nutrition Project. We thank all members of Child Nutrition Project in Kenya for their contribution to this work.

\section{References}

1. Ferguson EL, Gibson RS \& Opare-Obisaw C (1994) The relative validity of the repeated $24 \mathrm{~h}$ recall for estimating energy and selected nutrient intakes of rural Ghanaian children. Eur J Clin Nutr 48, 241-252.

2. Kigutha HN (1997) Assessment of dietary intake in rural communities in Africa, experiences in Kenya. Am J Clin Nutr 65, 1168S-1172S

3. Rose D, Meershoek S, Ismael C \& McEwan M (2002) Evaluation of a rapid field tool for assessing household diet quality in Mozambique. Food Nutr Bull 23, 181-189.

4. Nyambose J, Koski KG \& Tucker KL (2002) High intra/ interindividual variance ratios for energy and nutrient intakes of pregnant women in rural Malawi show that many days are required to estimate usual intake. J Nutr 132, 1313-1318.

5. Dop MC, Milan C, Milan C \& N'Diaye AM (1994) The 24-hour recall for Senegalese weanlings: a validation exercise. EurJ Clin Nutr 48, 643-653.

6. Neumann C, Bwibo NO \& Sigman M (1987) Diet Quantity and Quality. Functional Effects on Rural Kenyan Families. Kenya Project Final Report. Phase II - 1989-1992. Human Nutrition Collaborative Research Support Program. Los Angeles, CA: UCLA School of Public Health.

7. Parr CL, Barikmo I, Torheim LE, Ouattar F, Kaloga A \& Oshaug A (2002) Validation of the second version of quantitative food frequency questionnaire for use in western Mali. Public Health Nutr 5, 769-781.

8. Neumann CG, Bwibo NO, Murphy SP, Sigman M, Whaley S, Allen LH, Guthrie D, Weiss RE \& Demment MW (2003) Animal source foods improve dietary quality, micronutrient status, growth and cognitive function in Kenyan school children: background, study design and baseline findings. J Nutr 133, 3941S-3949S.

9. Calloway DH, Murphy SP, Bunch S \& Woerner J (1994) WorldFood Dietary Assessment System User's Guides. Berkeley, CA: University of California, Berkeley.

10. Bland JM \& Altman DG (1986) Statistical methods for assessing agreement between two methods of clinical measurement. Lancet 1, 307-310.

11. Altman DG (1991) Practical Statistics for Medical Research, 1st ed., pp. 403-409. New York: Chapman \& Hall/CRC.

12. Briefel R, Sempos C, McDowell M, Chien S \& Alaimo K (1997) Dietary methods research in the third National Health and Nutrition Examination Survey: underreporting of energy intake. Am J Clin Nutr 65, 1203S-1209S.

13. Subar A, Kipnis V, Troiano R et al. (2003) Using intake biomarkers to evaluate the extent of dietary misreporting in a large sample of adults: The OPEN study. Am J Epidemiol 158, $1-13$ 
14. Scagliusi F, Ferriolli E \& Lancha A (2006) Underreporting of energy intake in developing nations. Nutr Rev $\mathbf{6 4}$, 319-330.

15. Ferguson EL, Gadowsky SL, Huddle JM, Cullinan TR, Lehrfeld J \& Gibson RS (1995) An interactive 24-h recall technique for assessing the adequacy of trace mineral intakes of rural Malawian women; its advantages and limitations. Eur J Clin Nutr 49, 565-578.

16. Studenmund AH (2006) Using Econometrics. A Practical Guide, 5th ed., pp. 93-94. Boston, MA: Pearson Education Inc.
17. Beaton GH, Milner BA, Corey P et al. (1979) Source of variance in 24-hour dietary recall data: implications for nutrition study design and interpretation. Am J Clin Nutr 32, 2456-2559.

18. Murphy SP, Gewa C, Liang L, Grillenberger M, Bwibo NO \& Neumann CG (2003) School snacks containing animal source foods improve dietary quality for children in rural Kenya. J Nutr 133, 3950S-3956S.

19. Gewa C, Murphy SP \& Neumann CG (2007) Out-of-home food intake is often omitted from mothers' recalls of school children's intake in rural Kenya. J Nutr 137, 2154-2159. 